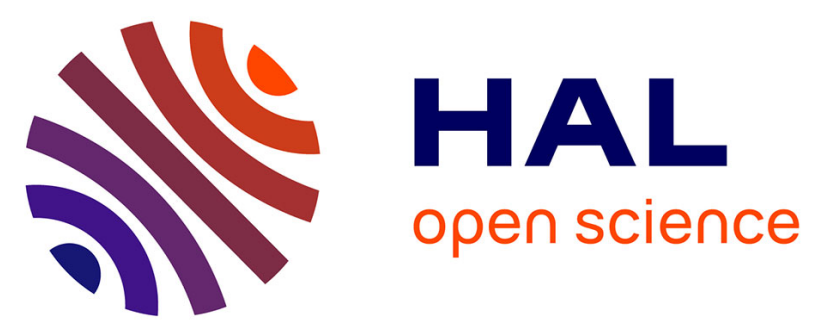

\title{
Application of nanofiltration hollow fibre membranes, developed by photografting, to treatment of anionic dye solutions
}

Ahmad Akbari, Sandrine Desclaux, Jean-Christophe Rouch, Jean-Christophe Remigy

\section{To cite this version:}

Ahmad Akbari, Sandrine Desclaux, Jean-Christophe Rouch, Jean-Christophe Remigy. Application of nanofiltration hollow fibre membranes, developed by photografting, to treatment of anionic dye solutions. Journal of Membrane Science, 2007, vol. 297 ( $\mathrm{n}^{\circ}$ 1-2), pp. 243-252. 10.1016/j.memsci.2007.03.050 . hal-01290378

\section{HAL Id: hal-01290378 \\ https://hal.science/hal-01290378}

Submitted on 18 Mar 2016

HAL is a multi-disciplinary open access archive for the deposit and dissemination of scientific research documents, whether they are published or not. The documents may come from teaching and research institutions in France or abroad, or from public or private research centers.
L'archive ouverte pluridisciplinaire HAL, est destinée au dépôt et à la diffusion de documents scientifiques de niveau recherche, publiés ou non, émanant des établissements d'enseignement et de recherche français ou étrangers, des laboratoires publics ou privés. 


\section{OATAO}

\section{Open Archive TOULOUSE Archive Ouverte (OATAO)}

OATAO is an open access repository that collects the work of Toulouse researchers and makes it freely available over the web where possible.

This is an author-deposited version published in : http://oatao.univ-toulouse.fr/ Eprints ID : 15609

To link to this article : DOI:10.1016/j.memsci.2007.03.050

URL : http://dx.doi.org/10.1016/j.memsci.2007.03.050

To cite this version : Akbari, Ahmad and Desclaux, Sandrine and Rouch, Jean-Christophe and Remigy, Jean-Christophe Application of nanofiltration hollow fibre membranes, developed by photografting, to treatment of anionic dye solutions. (2007) Journal of Membrane Science, vol. 297 (n 1-2). pp. 243-252. ISSN 0376-7388

Any correspondence concerning this service should be sent to the repository administrator: staff-oatao@,listes-diff.inp-toulouse.fr 


\title{
Application of nanofiltration hollow fibre membranes, developed by photografting, to treatment of anionic dye solutions
}

\author{
A. Akbari ${ }^{a}$, S. Desclaux ${ }^{b}$, J.C. Rouch ${ }^{\text {b }}$, J.C. Remigy ${ }^{\text {b,* }}$ \\ ${ }^{a}$ NanoSciTech Center, University of Kashan, Kashan, Iran \\ ${ }^{\mathrm{b}}$ Laboratoire de Génie Chimique, Université Paul Sabatier, CNRS UMR 5503, 118 Route de Narbonne, 31062 Toulouse Cedex 4, France
}

\begin{abstract}
New hollow fibre nanofiltration membranes have been developed by UV-photografting using sodium $p$-styrene sulfonate (NaSS) as a vinyl monomer. The influence of different parameters on the grafting process such as irradiation time, quantity of received UV energy by the membrane and addition of photoinitiator, on the performances and the characteristics of the membranes were examined. The molecular weight cut-off of the grafted hollow fibres was estimated using different PEG solutions. The grafted membranes were also evaluated for the removal of different anionic dyes (Acid, Direct and Reactive dyes) with an aim to reuse the dye and the water in the process house. It is observed that the newly developed hollow-fibre membranes show performances which are close to that of an "ideal" membrane adapted to the treatment of dye effluents. For example, a negatively charged hollow fibre with a $4500 \mathrm{Da}$ cut-off can be used to concentrate a saline direct red 80 solution with a high flux (15 $\left.10^{-5} \mathrm{lh}^{-1} \mathrm{~m}^{-2} \mathrm{~Pa}^{-1}\left(15 \mathrm{lh}^{-1} \mathrm{~m}^{-2} \mathrm{bar}^{-1}\right)\right)$, a high dye rejection $(R>97 \%)$ and a salt retention lower than $2 \%$.
\end{abstract}

Keywords: Membrane; Hollow fibre; Photografting; Nanofiltration; Textile dyes

\section{Introduction}

In the textile industry, there are several process operations for finishing of fabric which generate wastewater with various compositions. These operations include desizing, scouring, mercerizing, bleaching, dyeing or printing and finishing. Among all these wastewaters, the dyeing wastewater is more problematic due to the presence of dyes. The textile dyes are organic components which are usually toxic, non-biodegradable and they have ecosystem actions on the rivers [1]. Consequently, the treatment processes must be able to reduce the colour higher than $90 \%$.

There are three groups of textile dyes depending on their state in solution and on their charge: group $\mathrm{N}$; neutral dyes such as disperse, vat and sulphur dyes which are not soluble in water; group $\mathrm{C}$; cationic dyes like basic dyes and group $\mathrm{A}$; anionic dyes that is to say acid, direct and reactive dyes which are soluble in water. Treatment technologies for removing dye from wastewater are divided into several groups such as: coagulation,

\footnotetext{
* Corresponding author. Tel.: +33 5615576 18; fax: +33561556139. E-mail address: remigy@ chimie.ups-tlse.fr (J.C. Remigy).
}

biological, adsorption, oxidation, ion-exchange, electrochemical and membrane separation [2]. There are advantages and disadvantages associated with each of these techniques and not all are suitable for all dye classes.

However, because a membrane can act as a purely physical barrier to specific components without either the degradation of the components or the addition of chemicals, membrane separation, potentially allows the removal and reuse of dyes, chemicals, and process water. In this respect, membrane processes differ from the other generic groups.

Among all types of membrane operations, nanofiltration, due to the different mechanisms of retention allows to concentrate and reject soluble and ionic dyes such as acid, basic, direct and reactive dyes [3]. Microfiltration and ultrafiltration are suitable for removing of colloidal dyes such as disperse and vat dyes.

However, most of commercial nanofiltration membranes are polyamide based. The polyamide is a textile fibre polymer which can be dyed by the majority of textile dyes. Thus, using this type of nanofiltration membranes for the treatment of dyeing effluents causes membrane fouling and so flux decreases during filtration as it has been shown in a previous paper [4]. B. Van der Bruggen et al. have studied the performance of 
three nanofiltration membranes (cut-off: 180-250-800 Da) to the treatment of dyehouse effluents $[5,6]$. The membranes were NF70 (polyamide composite), UTC-20 (piperazineamide composite) and NTR 7450 (polyether sulfone sulfonate) with a molecular weight cut-off (MWCO) of 200, 180 and 600-800 Da, respectively. They have observed that the obtained flux by polyamide membranes (NF70 and UTC-20) has strongly decreased. They have attributed this decline to the osmotic pressure and the dye adsorption by membranes due to the presence of polyamide in the membrane surface.

Van der Bruggen et al. [6] have also examined the mechanisms of flux decline and dye retention of the same nanofiltration membranes. They have used a synthetic dye solution containing of reactive blue 2 (M.W.: $840 \mathrm{Da}$, three sulfonate groups), reactive orange 16 (M.W.: $617 \mathrm{Da}$, two sulfonate groups), $\mathrm{Na}_{2} \mathrm{SO}_{4}$, $\mathrm{Na}_{2} \mathrm{CO}_{3}, \mathrm{NaOH}$ and a surfactant. They have observed that salt retention was decreasing with a salt concentration increase due to the decrease of the Donnan effect. The flux was also dependent to salt concentration and it decreases rapidly with increasing of salt concentration: due to the important salt retention, the osmotic pressure difference is increased and consequently the flux also decreases.

This brief review of the literature leads us to conclude that:

- NF polyamide-based membranes are not suitable for the treatment of textile dye solutions due to fouling.

- NF membranes with a too low MWCO are also not suitable due to a too high salt retention.

An "ideal" membrane for the treatment of textile dye solutions would then have the following characteristics:

- A thin skin with a high density of charges of the same sign that the dyes to be retained (i.e. in order to obtain low fouling and high dye retention).

- A small retention of salt in order to avoid a too high osmotic pressure and a decrease of dye retention due to the decrease of the electrostatic part of dye retention.

In a previous paper, an attempt has been successfully made to prepare such an "ideal" flat sheet membrane by UV-photografting an ultrafiltration polysulfone membrane in presence of sodium $p$-styrene sulfonate $(\mathrm{NaSS})$ and [2(acryloyloxy)ethyl]trimethyl ammonium chloride (AO) [7]. By UV-photografting technique, chemicals bonds in the polysulfone membrane which is photo-reactive can be cleaved to create radical sites [8]. Free radical polymerisation will occur at these sites in presence of a vinyl monomer, and thus polymer chains are grafted to the membrane surface by covalent bond. In the present study, this method has been adapted for the modification of the external surface of hollow fibres using the photografted process elaborated at our laboratory $[9,10]$.

The choice of hollow fibre geometry with an outside-in mode of filtration has been made for the following reasons [11]:

- Hollow fibres can be assembled in large modules with large surface areas.
- An outside-in mode of filtration leads to an optimum small diameter hollow fibre giving the possibility to manufacture modules with a larger surface area than with an inside-out mode of filtration.

- With an outside-in mode of filtration, fouling is lower and backflushes are more efficient to remove cake layer than with an inside-out mode of filtration.

\section{Materials and methods}

\subsection{Photografting set-up}

Fig. 1 represents the UV-photografting set-up. The UF hollow-fibre membrane, initially wet by water, was dipped in the aqueous monomer solution (not degassed). Then the hollow fibre passed through two UV systems (model UVAPRINT LE S/CM, UV polychromatic lamp of F type, $25 \mathrm{~cm}$ length, Hoenle UV France, Lyon, France) where the photografting occurs under air. The line rate $\left(U, \mathrm{~m} \mathrm{~min}^{-1}\right)$ of the hollow fibre (production rate) is maintained constant at a value comprises between 2 and $20 \mathrm{~m} \mathrm{~min}^{-1}$. After irradiation, the hollow fibre was carefully, washed with reverse osmosis treated water.

The total energy $\left(E, \mathrm{~J} \mathrm{~m}^{-2}\right)$ received by the membrane is equal to the product of the intensity $\left(I_{\mathrm{UV}}, \mathrm{W} \mathrm{m}^{-2}\right)$ by the residence time or irradiation time $\left(T_{\text {irr }}, \mathrm{s}\right)$ in the reactor. The UV intensity was measured using an UV meter High End (Hoenle UV France, Lyon, France) equipped with UVA, UVB and UVC sensors. Energy given in this article is the total UV energy. A more complete description of these parameters can be found in reference [10].

\subsection{Filtration system}

Fig. 2 shows the tangential NF unit. From the feed tank (volume $5 \mathrm{~L}$ ), the feed solution is pumped to the hollow-fibre module. The module contains 10 fibres of $20 \mathrm{~cm}$ length. The retentate and permeate solutions are recycled to the feed tank so the feed concentration is constant. In the retentate line, a flow meter is placed to regulate the linear feed velocity $(u$, $\mathrm{m} \mathrm{s}^{-1}$ ). The feed flow rate was set between 65 and $260 \mathrm{Lh}^{-1}$. The desired pressure, adjusted by means of a pressure regulator,

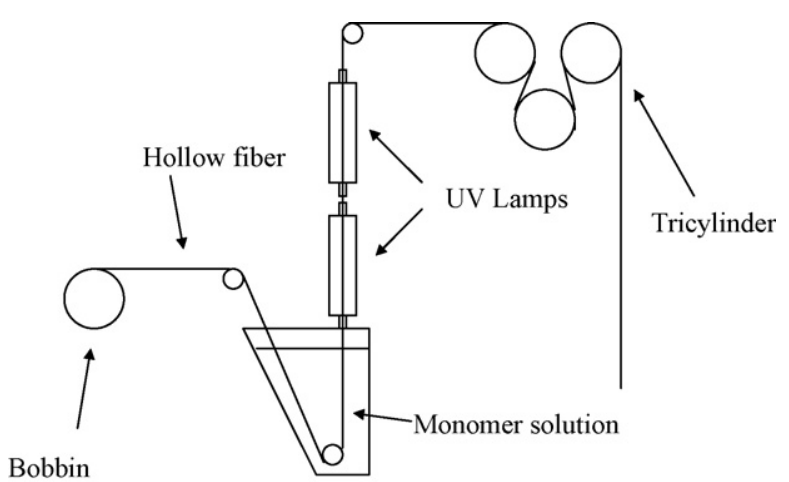

Fig. 1. Schema of the photoreactor set up. 


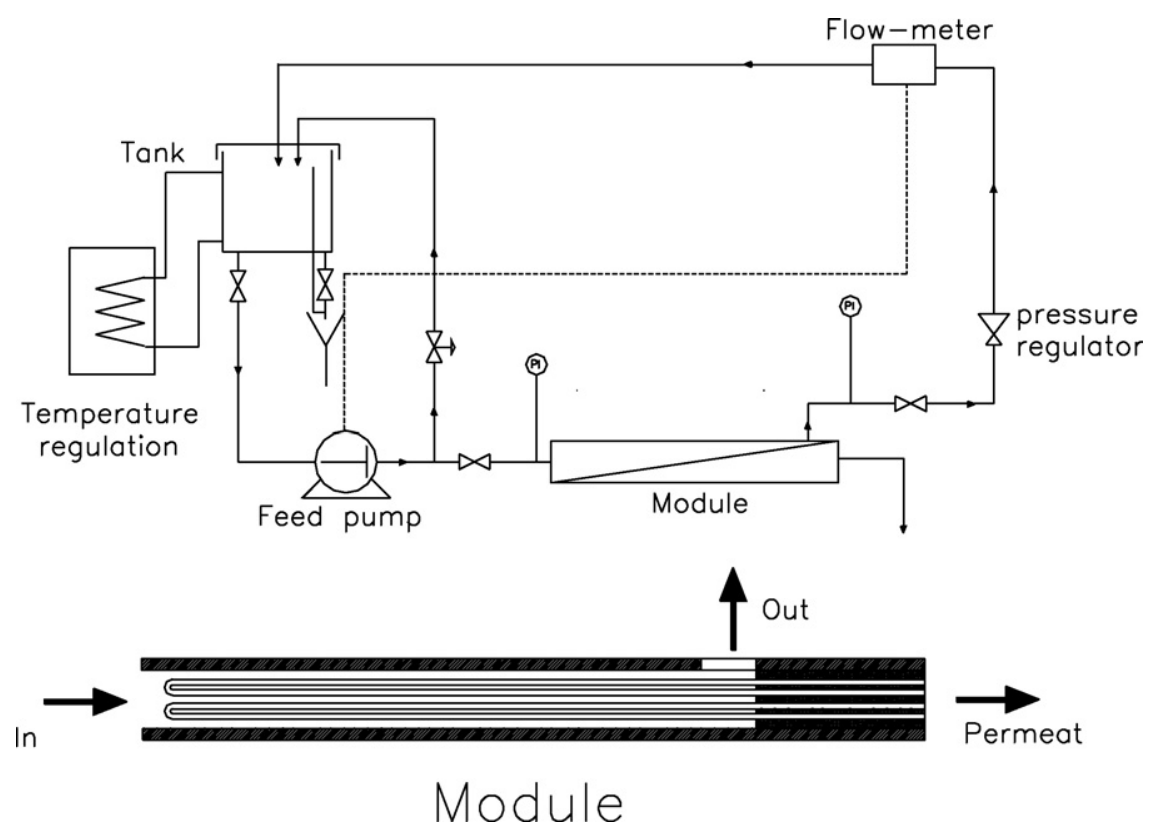

Fig. 2. Schema of the tangential nanofiltration unit and the hollow fibre module.

was varied in the range of $0.5-4 \times 10^{5} \mathrm{~Pa}(0.5-4$ bars $)$. The temperature of the feed solution is maintained at $25^{\circ} \mathrm{C}$. Excepted for the long time filtration (see Fig. 14), the flux and retention were measured during $60 \mathrm{~min}$, each $10 \mathrm{~min}$. The values reported here correspond to a stable flux which was achieved after 10 min.

\subsection{Materials}

\subsubsection{Support ultrafiltration hollow-fibre membranes}

Two hollow-fibre polysulfone membranes called $1 \mathrm{~A}$ and $2 \mathrm{~A}$ were home-made by phase inversion [13]. The characteristics of these hollow fibre membranes such as water permeability $\left(L_{\mathrm{p}}\right)$, intrinsic $10 \mathrm{kDa}$ PEG retention $\left(R_{\text {int }}\right)$ [14], inner $\left(d_{\text {in }}\right)$ and outer $\left(d_{\text {out }}\right)$ diameters are presented in Table 1 . The active surfaces of the HF modules are also given.

\subsubsection{Monomer, crosslinker and photoinitiator}

Sodium $p$-styrene sulfonate, $N, N^{\prime}$-methylene bis acrylamid (crosslinker, Ret) and 4-hydroxybenzophenone (photoinitiator, PI) were purchased from Aldrich and used as received without further purification. NaSS concentration $[\mathrm{NaSS}]$ is given in mass percent. Concentration of Ret [Ret] and PI [PI] are given in mole percent of moles of NaSS.

Table 1

Characteristics of support hollow fibre membranes (i.e. before photografting)

\begin{tabular}{lcc}
\hline Support hollow fibre & $1 \mathrm{~A}$ & $2 \mathrm{~A}$ \\
\hline$d_{\text {in }}(\mathrm{mm})$ & 0.60 & 0.65 \\
$d_{\text {out }}(\mathrm{mm})$ & 1.10 & 1.20 \\
$L_{\mathrm{p}}\left(\times 10^{-5} 1 \mathrm{~h}^{-1} \mathrm{~m}^{-2} \mathrm{~Pa}^{-1}\left(1 \mathrm{~h}^{-1} \mathrm{~m}^{-2} \mathrm{bar}^{-1}\right)\right)$ & 30 & 31 \\
$R_{\text {int }}(\%)$ PEG $10 \mathrm{kDa}$ & 65 & 87 \\
Active surface of module $\left(\mathrm{cm}^{2}\right)$ & 69.1 & 75.4 \\
\hline
\end{tabular}

\subsection{Membrane characterizations}

The water flux was measured by filtrating reverse osmosis treated water at different applied pressure between 0 and $3 \times 10^{5} \mathrm{~Pa}$ ( 0 and 3 bars).

The membrane characterization studies were carried out using a polyethylene glycol (PEG) series $(600,2000,4600$, $10,000 \mathrm{Da}$ ) (Aldrich, France) for MWCO measurement using the Causserand's protocol [14], with dye solution, with single salt solution $(\mathrm{NaCl})$ and mixture of dye and salt solutions. The observed retentions of the dyes and salt were measured under different pressures up to $3 \times 10^{5} \mathrm{~Pa}$ ( 3 bars) and different feed velocity $u\left(0.1-0.8 \mathrm{~m} \mathrm{~s}^{-1}\right)$.

The concentration of PEG was measured from Total Organic Carbon (TOC) of the single PEG solutions. TOC was measured using a carbon analyzer SHIMADZU model TOC 5050 A. The concentration of dye solutions were analyzed using an UV-vis spectrophotometer ANTHELIE SECOMAN (Domont, France) at the wavelength of the maximum absorption of each dye. Table 2 represents the main characteristics of the used dyes [12]. A concentration of $100 \mathrm{ppm}$ of dye in water has been used in all experiments. The choice of the concentrations was explained elsewhere [7]. The concentration of salt solutions was determined from the conductivity of solution.

Table 2

Characteristics of the dyes [12]

\begin{tabular}{llrll}
\hline Dye (supplier) & Symbol & $\begin{array}{l}\text { M.W. } \\
\text { (Da) }\end{array}$ & Charge & $\begin{array}{l}\text { [dye] } \\
(\mathrm{mM})\end{array}$ \\
\hline Acid orange10 (Aldrich) & AO10 & 452 & -2 & 0.22 \\
Direct red 80 (Ciba) & DR80 & 1373 & -6 & 0.07 \\
Direct yellow 8 (Aldrich) & DY8 & 518 & -1 & 0.19 \\
Reactive orange 16 (Aldrich) & RO16 & 617 & -1 & 0.16 \\
\hline
\end{tabular}


The degree of grafting (DG) was determined by an ionexchange capacity method [15]. After washing with reverse osmosis treated water in order to remove the not grafted monomers, $1 \mathrm{~m}$ length of grafted hollow-fibre was placed in $2 \mathrm{M} \mathrm{HCl}$ solution for $20 \mathrm{~h}$ to obtain the acid form of the sulfonic groups. The hollow fibre in $\mathrm{H}^{+}$form was then equilibrated in $0.05 \mathrm{M} \mathrm{NaCl}$ solution for $10 \mathrm{~h}$ at $20^{\circ} \mathrm{C}$. The amount of protons released in the solution, was measured using a $\mathrm{pH}$ meter. From the $\mathrm{pH}$ difference of the $\mathrm{NaCl}$ solution after and before equilibration, the degree of grafting was calculated. This analysis was made at least two times in order to have less than 5\% of difference between measurements. The degree of grafting is expressed in mmol of monomer per $\mathrm{m}^{2}$ of membrane.

\section{Results and discussion}

\subsection{Photografting}

\subsubsection{Irradiation of hollow-fibre membranes in absence of monomer}

The hollow fibre membrane (2A) was irradiated in absence of monomer, at received UV energies between 200 and $350 \mathrm{~kJ} \mathrm{~m}^{-2}$ to investigate the photo degradation of the PSf hollow fibre membrane. Results for the pure water permeability and the observed retention of PEG as a function of the received energy are shown in Fig. 3. One can observe that the water permeability and the PEG retention both decrease when the total received energy increases. This simultaneous decline has already been observed for polyethersulfone membranes and was attributed to competition between two phenomena: crosslinking and chain scission [16]. The crosslinking of the PSf chains decreases the water permeability (i.e. closing the small pores) while chain scissions are responsible for the loss of membrane selectivity (i.e. opening the big pores).

\subsubsection{Effect of received energy}

3.1.2.1. Energy monitored by the UV intensity. Several modified hollow-fibre membranes were prepared from the 1A hollow fibre membrane at the same monomer concentration $(15 \%)$ and line rate $\left(3 \mathrm{~m} \mathrm{~min}^{-1}\right)$ but at different received energies (i.e. dif-

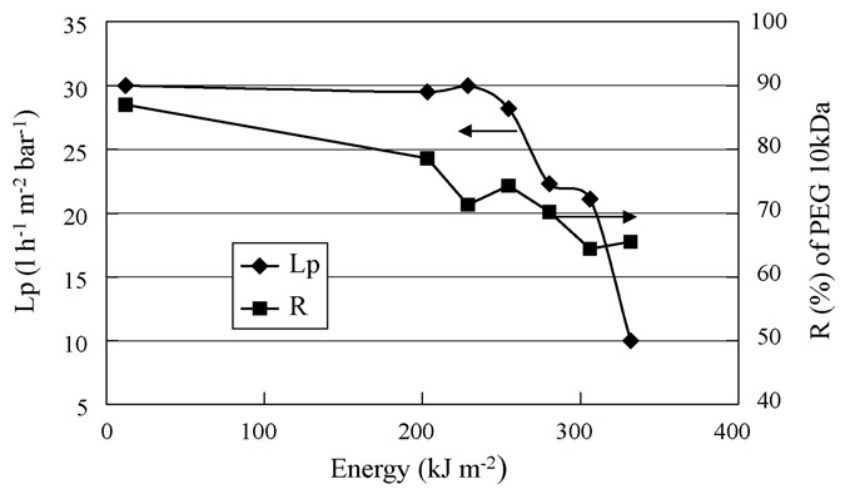

Fig. 3. Pure water permeability $\left(L_{\mathrm{p}}\right)$ and observed retention $(R)$ of PEG $10 \mathrm{kDa}$ (applied pressure: $1 \times 10^{5} \mathrm{~Pa}(1 \mathrm{bar})$ and $\left.25^{\circ} \mathrm{C}\right)$ of $2 \mathrm{~A}$ hollow fibre membrane irradiated in absence of monomer vs. received UV energy (line rate: $7.5 \mathrm{~m} \mathrm{~min}^{-1}$ ).

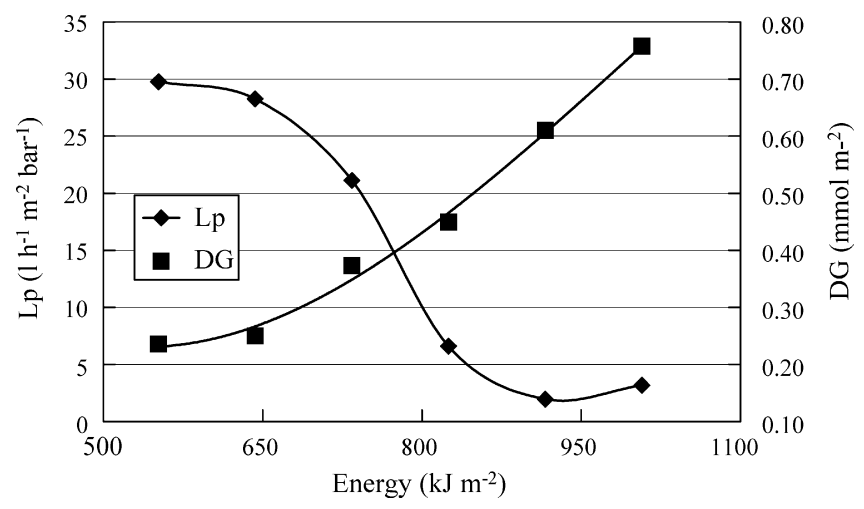

Fig. 4. Degree of grafting (DG) and pure water permeability $\left(L_{\mathrm{p}}, 25^{\circ} \mathrm{C}\right)$ of grafted $1 \mathrm{~A}$ hollow fibre membranes vs. received UV energy (line rate: $3 \mathrm{~m} \mathrm{~min}^{-1}$, $[\mathrm{NaSS}]=15 \%,[$ Ret $]=2 \%)$.

ferent UV intensities). Fig. 4 shows the water permeability and the degree of grafting as a function of the energy. Goma-Bilongo et al. [10] showed that when the line rate is constant, the concentrations of monomer at the membrane and/or in the pore are constant. So the observations only depend of the UV intensity effect. The results show that the degree of grafting increases with the increase of energy, while the water permeability decreases. However, for high energies (larger than $900 \mathrm{~kJ} \mathrm{~m}^{2}$ ), the permeability remains constant while the dg still increases. This point is not clearly understood and is probably due to the presence of large pores (i.e. a broad pore size distribution) which are closed with difficulty by the grafted layer. This assumption is partially confirmed by the MWCO measurements of the selected fibre: the retention of $10 \mathrm{kDa}$ PEG is not total (see Fig. 7).

3.1.2.2. Energy monitored by the line rate. Fig. 5 represents the variation of the permeability and the degree of grafting of the 1 A polysulfone membrane modified by UV photo grafting at the same monomer concentration (15\%) according to the received

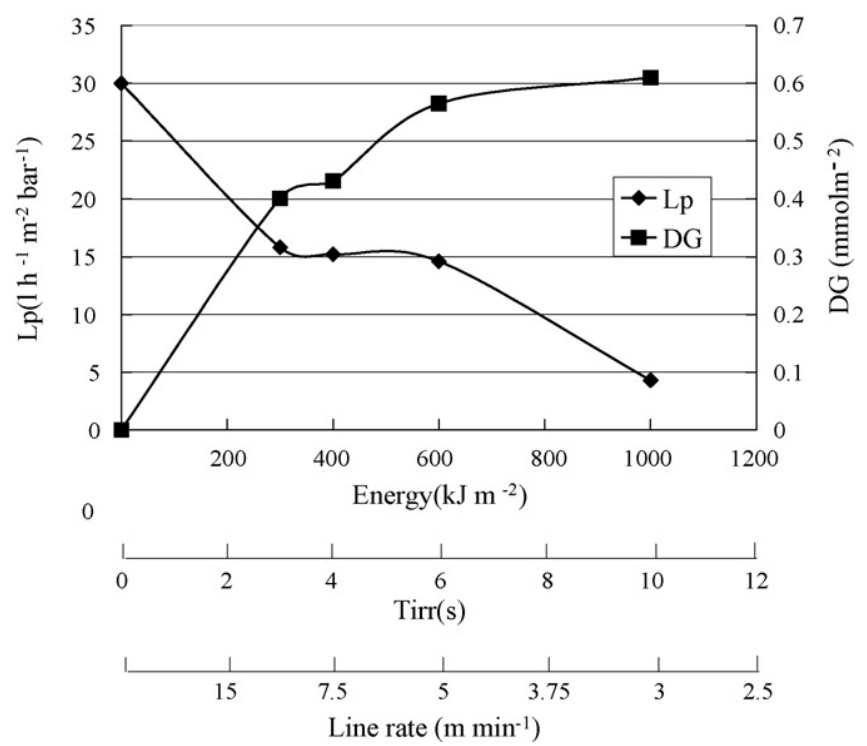

Fig. 5. Degree of grafting (DG) and pure water permeability $\left(L_{\mathrm{p}}, 25^{\circ} \mathrm{C}\right)$ grafted 1A hollow fibre membranes as a function of received UV energy, irradiation time and line rate (UV intensity $I_{\mathrm{UV}}=100 \mathrm{~kW} \mathrm{~m}^{-2},[\mathrm{NaSS}]=15 \%,[$ Ret $]=2 \%$ ). 
energy monitored by variation of the line rate (and consequently by the irradiation time, $T_{\mathrm{irr}}$ ). As before, it is observed that the degree of grafting increases with the increase of energy while the water permeability decreases.

Measurements for an energy of $1000 \mathrm{~kJ} \mathrm{~m}^{-2}$ $\left(\mathrm{DG}=0.6 \mathrm{mmol} \mathrm{m}^{-2} ; \quad L_{\mathrm{p}}=4 \times 10^{-5} \mathrm{lh}^{-1} \mathrm{~m}^{-2} \mathrm{~Pa}^{-1}\right.$ $\left.\left(41 \mathrm{~h}^{-1} \mathrm{~m}^{-2} \mathrm{bar}^{-1}\right)\right)$ correspond to a line rate of $3 \mathrm{~m} \mathrm{mn}^{-1}$ and are then directly comparable to the same measurements shown in Fig. 4 ( $\mathrm{DG}=0.75 \mathrm{mmol} \mathrm{m}^{-2} ; L_{\mathrm{p}}=3 \times 10^{-5} \mathrm{lh}^{-1} \mathrm{~m}^{-2} \mathrm{~Pa}^{-1}$ $\left.\left(31 \mathrm{~h}^{-1} \mathrm{~m}^{-2} \mathrm{bar}^{-1}\right)\right)$. Discrepancies can be attributed to the different batch of $1 \mathrm{AG}$ fibre and to experiments made at several months interval (cumulative small differences on line rate, temperature, monomer concentration and UV lamp power).

On the contrary, the measurements for the other energies were not performed at the same line rate and the results are very different. For example, results for energy of $600 \mathrm{~kJ} \mathrm{~m}^{-2}$ are $\mathrm{DG}=0.25 \mathrm{mmol} \mathrm{m}^{-2}$ (Fig. $4, U=3 \mathrm{~m} \mathrm{~s}^{-1}$ ) and $\mathrm{DG}=0.55 \mathrm{mmol} \mathrm{m}^{-2}$ (Fig. $5, U=5 \mathrm{~m} \mathrm{~s}^{-1}$ ): this means that the line rate increase, tend to increase the grafting ratio (and consequently the permeability decreases). This observation is of a great practical importance since the efficiency of the grafting increases with the increase of the productivity of the spinning/modification line.

Explanation for such remarkable result can be qualitatively explained from the theory of the photo grafting process by dip coating. The observations are the consequence of the variations of UV energy, of the monomer concentration and of the thickness of the deposited liquid film. When $\mathrm{U}$ is increased, the reduction in UV energy is composed by the increase of the monomer concentration at the surface and in the pore due to the increase of the film thickness [10]. The data shown in Figs. 4 and 5 lead to the conclusion that, in this case, the grafting efficiency is mostly dependent on the amount of monomer presents at the surface (with a thickness of few micrometers).

\subsubsection{Photografting in presence of photoinitiator}

The addition of a photoinitiator (PI) makes it possible to create radicals in the solution deposited on the membrane and thus to increase the kinetics and the quantity of created polymer chains on the surface. Goma showed that the thickness of the deposited layer is a function of the viscosity and the surface tension of the monomer solution and the line rate through the capillary number [10]. The thickness is thus higher than $10 \mu \mathrm{m}$ and increased with the line rate.

Two sources of radicals will be thus available: on the surface of the membrane due the photoactivity of PSf and inside the entrained solution. The presence of crosslinking agent should make it possible to establish links between the chains of created polymers inside the solution and those created onto the surface of the membrane; interest being to keep chemical bonds between the support membrane and the living polymer.

Fig. 6 represents the variation of the hydraulic permeability and the degree of grafting of modified 2A hollow fibres in presence and absence of photoinitiator according to the received energy by the membrane (monitored by the line rate). Table 3 shows the intrinsic retention of PEG $(10 \mathrm{kDa})$ with and without PI for two line rates ( 4 and $5 \mathrm{~m} \mathrm{~min}^{-1}$ or 750 and $600 \mathrm{~kJ} \mathrm{~m}^{-2}$ ).

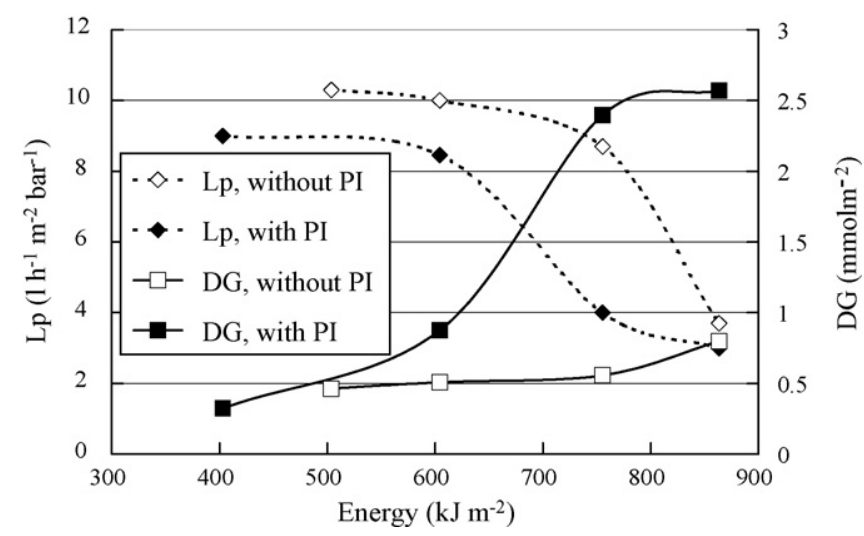

Fig. 6. Degree of grafting (DG) and pure water permeability $\left(L_{\mathrm{p}}, 25^{\circ} \mathrm{C}\right)$ grafted $2 \mathrm{~A}$ hollow fibre membranes vs. received energy in with and without photoinitiator $(\mathrm{PI})\left(\mathrm{UV}\right.$ intensity $\left.I_{\mathrm{UV}}=100 \mathrm{~kW} \mathrm{~m}^{-2},[\mathrm{NaSS}]=15 \%,[\operatorname{Ret}]=2 \%,[\mathrm{PI}]=2 \%\right)$.

These results show that:

- In the presence of photoinitiator, the degree of grafting is much more important than in absence of photoinitiator, in particular at the low line rate (i.e. high UV energy, by a factor 5 at $860 \mathrm{~kJ} \mathrm{~m}^{-2}$ ).

- The hydraulic permeability decreases according to the received energy in presence or absence of photoinitiator. The permeability decrease is higher in presence of PI.

- The retention of $10 \mathrm{kDa}$ PEG is higher in presence of PI considering the same UV energy (and probably for a same obtained permeability).

The higher degree of grafting obtained in presence of PI is due to the combined effects of a higher kinetic and a photo polymerisation that occurs both in the coated solution and at the surface of the membrane. The thickness of the coated solution is far higher (more than 10 times) than the thickness of the reaction zone at the surface of the membrane $[10,13]$. One can conclude that the thickness of the grafting layer is higher in presence of PI because the grafted polymers are produced at the surface of the membrane and in the coated film (i.e. coated solution).

The efficiency of the grafting layer in term of pore closing is different in presence or in absence of PI. In absence of PI, the growth of the grafted layer starts starting from the surface of the pore in absence of PI (i.e. the initiation of the polymerisation occurs at the surface of the pore). A pore is progressively closed by the increase of the grafting layer at the surface of the pore (i.e. from the surface). In presence of PI, the initiation occurs both at the surface and in the liquid film. A pore is progressively closed by the increase of the grafting layer at the surface and by the synthesis of polymer chains over the pore.

Table 3

Effect of photoinitiator on PEG $10 \mathrm{kDa}$ retention

\begin{tabular}{llll}
\hline Line rate $\left(\mathrm{m} \mathrm{min}^{-1}\right)$ & UV energy $\left(\mathrm{kJ} \mathrm{m}^{-2}\right)$ & Without PI $(\%)$ & With PI (\%) \\
\hline 4 & 750 & 76 & 96 \\
5 & 600 & 72 & 84 \\
\hline
\end{tabular}


Table 4

Photogreffage conditions and characterizations of grafted hollow fibre membranes

\begin{tabular}{llcc}
\hline Grafted hollow fibre & Name & 1AG & 2AG \\
\hline \multirow{5}{*}{ Grafting conditions } & Line rate $\left(\mathrm{m} \mathrm{min}^{-1}\right)$ & 7.5 & 4 \\
& $T_{\text {irr }}(\mathrm{s})$ & 4 & 7.5 \\
& Received energy by membrane & 366.5 & 755.4 \\
& $\left(\mathrm{~kJ} \mathrm{~m}^{-2}\right)$ & & \\
& {$[\mathrm{NaSS}](\%)$} & 15 & 15 \\
& {$[$ Ret] $(\%)$} & 2 & 2 \\
& {$[\mathrm{PI}](\%)$} & 0 & 2 \\
& Degree of grafting $\left(\mathrm{mmol} \mathrm{m}^{-2}\right)$ & 0.43 & 2.45 \\
Characterizations & $L_{\mathrm{p}}\left(\times 10^{-5} \mathrm{lh}^{-1} \mathrm{~m}^{-2} \mathrm{~Pa}^{-1}\right.$ & 15 & 4 \\
& $\left.\left(1 \mathrm{~h}-1 \mathrm{~m}^{-2} \mathrm{bar}^{-1}\right)\right)$ & & \\
& $\mathrm{MWCO}^{-\mathrm{Da})}$ & 4600 & 2000 \\
\hline
\end{tabular}

Consequently the permeability decrease is higher and the retention is higher in presence of PI: the efficiency in term of pore closing is higher in presence of PI for a given UV energy. However, with PI, a far higher DG is needed to get the same permeability decrease $\left(2.5 \mathrm{mmol} \mathrm{m}^{-2}\right.$ compared to $0.8 \mathrm{mmol} \mathrm{m}^{-2}$ to get permeability around $3-4 \times 10^{-5} 1 \mathrm{~h}^{-1} \mathrm{~m}^{-2} \mathrm{~Pa}^{-1}\left(3-41 \mathrm{~h}^{-1} \mathrm{~m}^{-2}\right.$ bar $\left.\left.^{-1}\right)\right)$ because the surface porosity is low for this kind of membrane (less $5 \%$ ): most of the grafted polymer is not used to close the pores but is simply grafted on surface without pore.

\subsection{Characterisation of the selected hollow fibre membranes}

Among all the modified hollow fibres, two were selected for filtration of coloured solutions: the first one is the 1A membrane support which was grafted at a rate of $7.5 \mathrm{~m} \mathrm{~min}^{-1}$ with an energy of $366 \mathrm{~kJ} \mathrm{~m}^{-2}$ and without photoinitiator, the second one was prepared from the grafted membrane $2 \mathrm{~A}$ at the rate of $4 \mathrm{~m} \mathrm{~min}^{-1}$, with energy of $755 \mathrm{~kJ} \mathrm{~m}^{-2}$ and in the presence of photoinitiator (Table 4). These hollow fibres will be called $1 \mathrm{AG}$ and $2 \mathrm{AG}$, respectively.

In the range of pressures available on the NF set-up, no compaction is observed. The average permeability of the $1 \mathrm{AG}$ and $2 \mathrm{AG}$ grafted hollow fibres are, respectively, 15 and $4 \times 10^{-5} 1 \mathrm{~h}^{-1} \mathrm{~m}^{-2} \mathrm{~Pa}^{-1}\left(15\right.$ and $\left.41 \mathrm{~h}^{-1} \mathrm{~m}^{-2} \mathrm{bar}^{-1}\right)$. The molecular weight cut-off measured by filtration of PEG solutions, are presented in Fig. 7. The MWCO of these membranes (4600 and 2000 Da for $1 \mathrm{AG}$ and $2 \mathrm{AG}$ membranes, respectively) are higher than the molecular weight of the used dyes (Table 2), the sieving retention mechanism for dyes will be thus limited particularly for the $1 \mathrm{AG}$ hollow fibre membrane.

\subsection{Application to the treatment of dye solutions}

\subsubsection{Dye retention}

The retention of different anionic dyes by the $1 \mathrm{AG}$ hollow fibre membrane at feed velocity of $0.8 \mathrm{~m} \mathrm{~s}^{-1}$ and pressure of $3 \times 10^{5} \mathrm{~Pa}$ ( 3 bars), are presented in Table 5 . The high retention ( $\sim 100 \%$ ) for DR80 can be ascribed to the high molecular weight (1373 Da) and the number of sulfonate groups (six groups). The

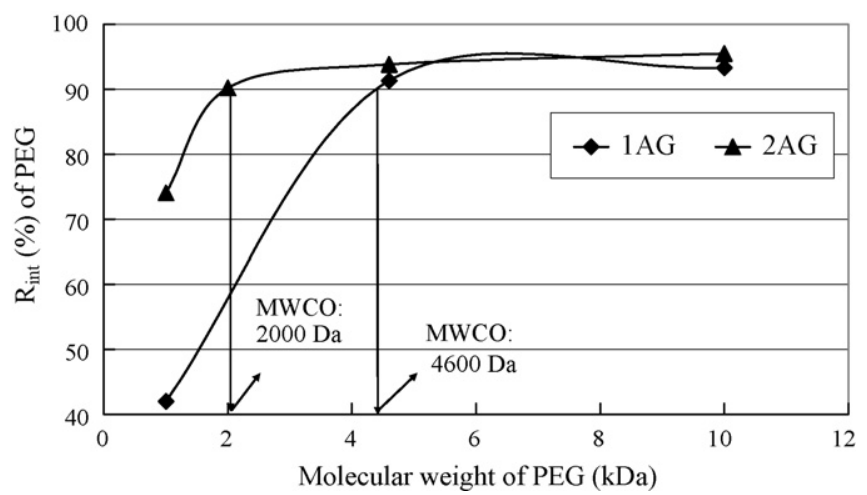

Fig. 7. PEG retention as a function of molecular weight of PEG of two grafted hollow fibre membranes $1 \mathrm{AG}$ and $2 \mathrm{AG}$.

retention for $\mathrm{AO} 10$ and $\mathrm{RO} 16$ was lower than that for DR80 because of their lower molecular weight and in particularly, lower charge density (two sulfonate groups). In this case, the sieving mechanism is slightly less important and dye retention takes place by an ionic exclusion mechanism [17]. Whereas the dyes DR80, AO10 and RO16 have retention corresponding to their charge or/and their molecular weight, the behaviour of direct yellow 8 (DY8) is remarkable. This dye has a low charge (one sulfonate group) and a molecular weight close to that of dyes AO10 and RO16. The high retention is related to the fact that this dye, used such as in textile industry, is an impure product; the solution of DY8 in distilled water is clear and limpid but addition of salt $\left(\mathrm{NaCl}\right.$ or $\left.\mathrm{MgSO}_{4}\right)$ leads to the formation of flocs (or aggregation). After settling of the flocs, a complete discoloration of the solution is observed while all the coloration is limited to the flocs. The solution of DY8 is thus not that of a pure dye but a mix of a soluble dye and colloidal particles. The strong retention of this dye could thus be explained by the retention of the colloids (aggregated particles) on which would be sorbed most of the soluble dye.

\subsubsection{Effect of concentration polarisation}

The influence of the concentration polarisation was studied by varying the feed velocity $\mathrm{u}$ in the module, at pressure of $3 \times 10^{5} \mathrm{~Pa}$ (3 bars), for four dye solutions using the $1 \mathrm{AG}$ membrane (Fig. 8(a and b)) and at two pressures ( 2 and $3 \times 10^{5} \mathrm{~Pa}, 2$ and 3 bars) for acid orange 10 using the $2 \mathrm{AG}$ membrane (Fig. 9). From these plots, it is observed that the increase of feed velocity increases the flux and the dye retention for the two hollow fibre membranes; this is in particularly true for the low molecular weight dyes such as AO10 and RO16. The increase of feed velocity makes it possible to decrease the concentration at the membrane surface leading to a decrease in permeate concentra-

Table 5

Observed retention of different dye solutions for the two grafted hollow fibre membranes (pressure $4 \times 10^{5} \mathrm{~Pa}$ (4 bars), $u=0.8 \mathrm{~m} \mathrm{~s}^{-1}$, [dye] $=100 \mathrm{ppm}$, Temp. $\left.25^{\circ} \mathrm{C}\right)$

\begin{tabular}{lcccc}
\hline Membrane & DR80 & DY8 & AO10 & RO16 \\
\hline 1AG & 99.6 & 99.8 & 96.4 & 94.0 \\
AG & - & - & 98.0 & - \\
\hline
\end{tabular}



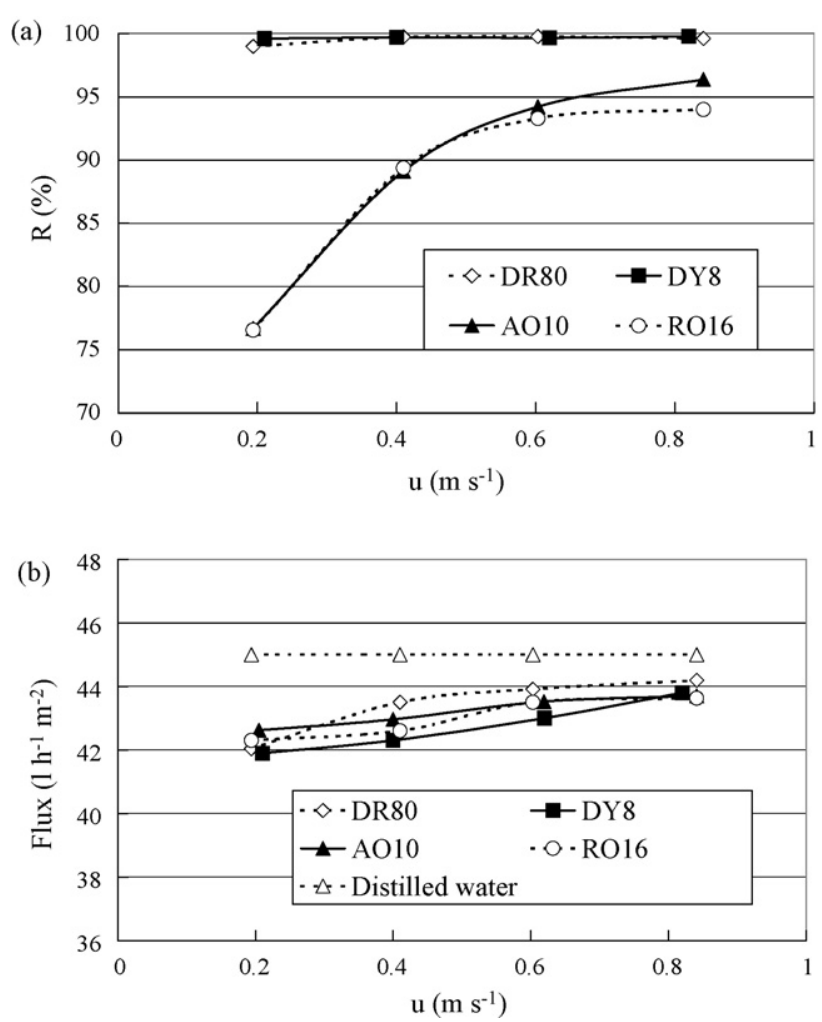

Fig. 8. (a) Observed dye retention $(R)$ and (b) solution flux of dye solutions vs. linear feed velocity $(u)$ for $1 \mathrm{AG}$ hollow fibre membrane ([dye] $=100 \mathrm{ppm}$, applied pressure: $3 \times 10^{5} \mathrm{~Pa}$ ( 3 bars), Temp.: $25^{\circ} \mathrm{C}$ ).

tion (and then an increase in retention). This lower concentration polarisation leads also to an osmotic pressure decrease and consequently an increase in the effective pressure and thus in an increase of the flux. It should be noted that, as the dye concentrations are low $(100 \mathrm{ppm})$, the osmotic pressure is small in comparison with the applied pressure, even at the membrane surface. So the effect of feed velocity (i.e. decrease of the concentration at the membrane surface) on flux is low (i.e. solution flux close to the pure water flux) whereas the dye retention increased significantly. It is to point out that the flux for the dye solutions are quite close to the distilled water flux, especially at high velocity; this means that fouling is negligible. In any case, no

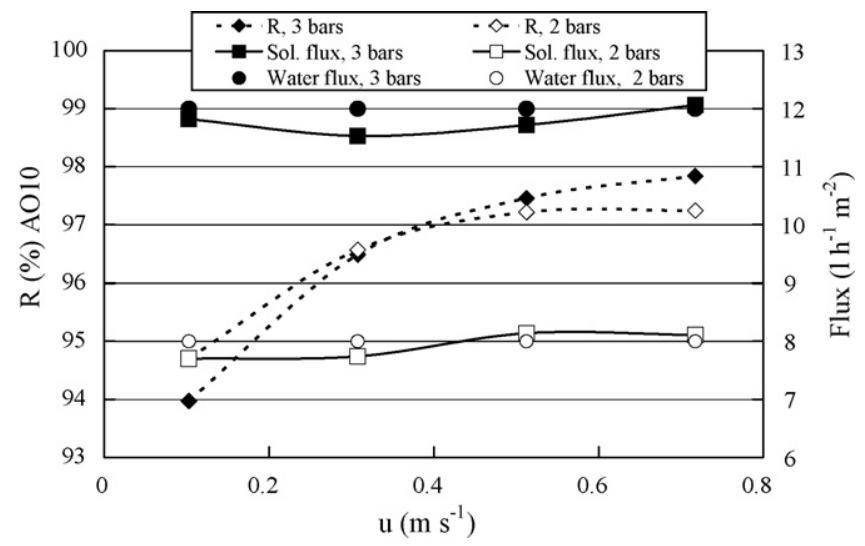

Fig. 9. AO10 solution: Observed retention $(R)$ and solution flux vs. linear feed velocity $(u)$ for $2 \mathrm{AG}$ hollow fibre membrane ([dye] $=100 \mathrm{ppm}$, Temp.: $25^{\circ} \mathrm{C}$ ). adsorption of dye on the membranes surface was observed as previously reported on flat sheet grafted membranes [7].

Concentration polarisation has a remarkable effect on the retention of dyes which are partially retained. The charge effects strongly decrease with the increase in the ion concentration and thus in the concentration polarisation for the aqueous charged solutions. The retention obtained with $1 \mathrm{AG}$ membrane for dyes $\mathrm{AO} 10$ and RO16 are due to electrostatic repulsion because the molecular weight of the dyes is close to 500-600 Da while the MWCO of 1 AG membrane is $4600 \mathrm{Da}$. The use of this membrane for the filtration of these dyes requires a good control of the concentration polarisation.

Fig. 9 presents the retention of AO10 by the $2 \mathrm{AG}$ hollow fibre at two applied pressures for various feed velocities. The effects of the concentration polarisation are qualitatively the same ones as previously reported but quantitatively the retention of $\mathrm{AO} 10$ varies only from $3 \%$ whereas for the $1 \mathrm{AG}$ membrane, the variation is $20 \%$ for the same variation in velocity (from 0.2 to $0.7 \mathrm{~m} \mathrm{~s}^{-1}$ ). Considering that fluxes are measured to more or less $10 \%$, one can say that the flux is relatively constant for the $2 \mathrm{AG}$ hollow fibre whereas it increases slightly for $1 \mathrm{AG}$ hollow fibre. Theses differences in behaviour are due to:

A low flux for $2 \mathrm{AG}$ membrane: thus the retro diffusion is enough to limit the concentration polarisation. On the contrary, the convection flux through the membrane is higher in the case of the 1AG membrane (approximately four times higher at $3 \times 10^{5} \mathrm{~Pa}(3$ bars $\left.)\right)$ : the concentration polarisation is then more important.

- The MWCO of the 2AG membrane (2000 Da) closer to the size of the dye associated with an important degree of grafting ( $2.45 \mathrm{mmol} \mathrm{m}^{-2}$ instead of $0.43 \mathrm{mmol} \mathrm{m}^{-2}$ for $1 \mathrm{AG}$ ): the $2 \mathrm{AG}$ membrane is thus higher charged with smaller pores than the $1 \mathrm{AG}$ membrane. As a consequence, $\mathrm{AO} 10$ retention is higher with $2 \mathrm{AG}$ membrane.

The $1 \mathrm{AG}$ hollow fibre thus shows retention lower than that of $2 \mathrm{AG}$ hollow fibre for AO10. The retention varies strongly when the concentration polarisation increases owing to the fact that the membrane is less charged and its MWCO is too large. This membrane can be used with high retention and flux in the case of the filtration of dyes when the concentration polarisation is low (high feed velocity; $0.8 \mathrm{~m} \mathrm{~s}^{-1}$ ). However, the textile effluents are saline solutions, the retention of dye should thus strongly decrease due to the shielding of carried charges by the membrane. 2AG hollow fibre is more powerful in term of retention; fluxes are nevertheless weaker. This membrane which is higher charged and has a lower MWCO should maintain important retention of the dyes for the filtration of saline coloured solutions.

\subsubsection{Effect of salt on the flux and dye retention}

As already mentioned, the coloured effluents of the textile industry are saline. The quantity of salt used for the dyeing operation depends on the type of dye and the number of sulfonate groups carried by the dye. Mainly sodium chloride is used. The results presented in this paragraph were performed with solu- 

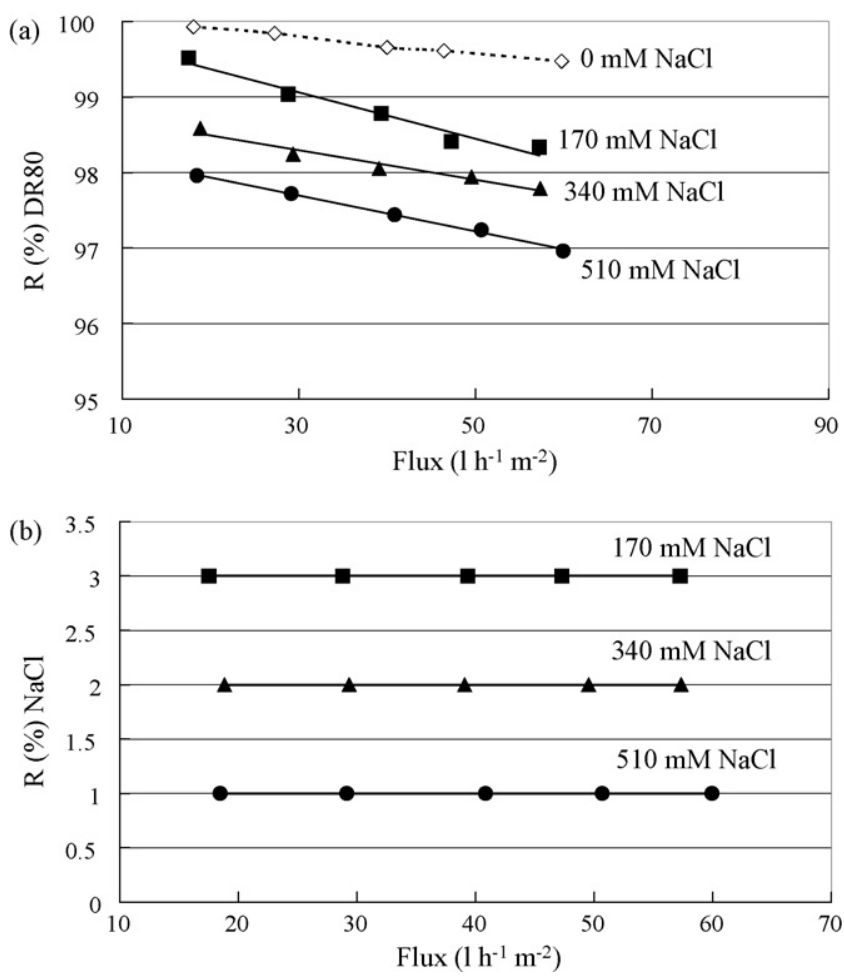

Fig. 10. Observed retention of DR80 (a) and $\mathrm{NaCl}$ (b) as a function of flux and $\mathrm{NaCl}$ concentration for $1 \mathrm{AG}$ hollow fibre membrane ([dye] $=100 \mathrm{ppm}$, $[\mathrm{NaCl}]=170 \mathrm{mM}, u=0.41 \mathrm{~m} \mathrm{~s}^{-1}$, Temp.: $\left.25^{\circ} \mathrm{C}\right)$.

tions of the same concentration in dye (100 ppm) but various concentrations in sodium chloride. The effect of the sodium chloride concentration on the permeability and the retention of DR80 with 1AG hollow fibre are represented in Fig. 10(a): the retention is plotted versus the flux (which is obtained by increasing the operating pressure).

One can note that, when the salt concentration increases, flux remains constant for a given pressure (points taken vertically) because of the low retention $(\sim 1-3 \%)$ of the salt (Fig. 10b). The concentration polarisation for salt is thus non-existent. The osmotic pressure is low and constant (the osmotic pressure due to $\mathrm{NaCl}$ varies from 0.25 to $0.33 \times 10^{5} \mathrm{~Pa}(0.25$ to 0.33 bars $)$ according to the concentration and the retention of salt). The retention of the DR80 decreases with the flux (concentration polarisation) and also decreases with an increase in the salt concentration that this decrease in range of salt concentration from 0 to $510 \mathrm{mM}$ is not very important. This effect is due to the shielding of the fixed charges of the membrane by the cations and the anions present in the solution. However, in the range of the salt concentrations used, which are representative of the concentrations for a real effluent, dye retention remains higher than $97 \%$ at concentration of $510 \mathrm{mM} \mathrm{NaCl}$ and pressure of $3 \times 10^{5} \mathrm{~Pa}$ (3 bars).

Fig. 11 represents the influence of the $\mathrm{NaCl}$ concentration on the retention of AO10 according to flux for the $1 \mathrm{AG}$ hollow fibre. The $\mathrm{NaCl}$ concentration is equal to $170 \mathrm{mM}$. AO10 is an anionic dye like DR80 but it has a lower molecular weight and is less charged (only 2 sulfonate groups against six for DR80). Unlike DR80 retention, the AO10 retention decreases strongly

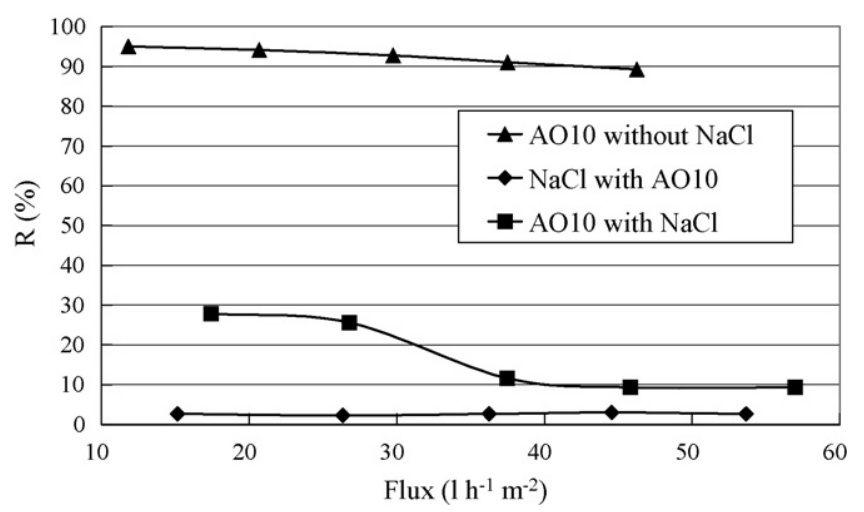

Fig. 11. Observed retention of $\mathrm{AO} 10$ and of $\mathrm{NaCl}$ as a function of flux for $1 \mathrm{AG}$ hollow fibre membrane $\left([\right.$ dye $]=100 \mathrm{ppm},[\mathrm{NaCl}]=170 \mathrm{mM}, u=0.41 \mathrm{~m} \mathrm{~s}^{-1}$, Temp.: $25^{\circ} \mathrm{C}$ ).

in the presence of salt while $\mathrm{NaCl}$ retention is still negligible. This decline is worsened by the concentration polarisation due to the increase in flux. The influence of the presence of salt is much more important in the case of AO10 than in that of DR80 because the molecular weight of AO10 is much lower than that of DR80. The sieving retention mechanism is less important and do not allow to compensate for the reduction in the ionic exclusion mechanism.

The use of the 2AG hollow fibre for the filtration of the same solution $(\mathrm{AO} 10+170 \mathrm{mM} \mathrm{NaCl})$ makes it possible to obtain retention of AO10 ranging between 85 and $80 \%$ (Fig. 12). The retention of $\mathrm{AO} 10$ and $\mathrm{NaCl}$ decreases according to the $\mathrm{NaCl}$ concentration while fluxes remain stables. The fluxes at 2 and $3 \times 10^{5} \mathrm{~Pa}(2$ and 3 bars) are equals, respectively, to 7.6 and $11.4 \mathrm{lh}^{-1} \mathrm{~m}^{-2}$. No important decline in the dye retention is observed here because on the one hand, the membrane is more charged than $1 \mathrm{AG}$ and on the other hand the MWCO of $2 \mathrm{AG}$ is closer to the molecular weight of this dye than the MWCO of $1 \mathrm{AG}$. Then for the $2 \mathrm{AG}$ hollow fibre, the sieving mechanism makes it possible to compensate for the loss of ionic exclusion. Nevertheless, it is not possible, with these experiments, to give the relative importance of the two mechanisms. So the different behaviours of the $1 \mathrm{AG}$ and $2 \mathrm{AG}$ during the filtration of $\mathrm{AO} 10$ in presence or in absence of salt are due to the lower MWCO and

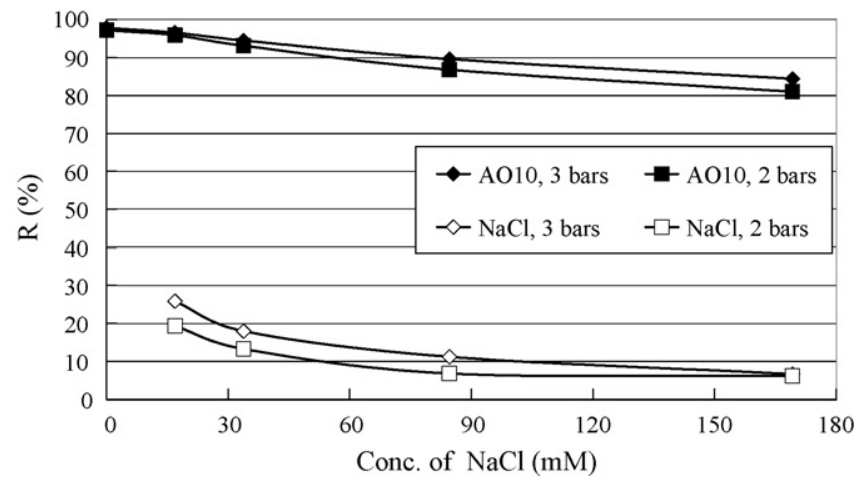

Fig. 12. Observed retention of $\mathrm{AO} 10$ and of $\mathrm{NaCl}$ as a function of $\mathrm{NaCl}$ concentration and applied pressure for $2 \mathrm{AG}$ hollow fibre membrane ([dye] $=100 \mathrm{ppm}$, $u=0.41 \mathrm{~m} \mathrm{~s}^{-1}$, Temp.: $\left.25^{\circ} \mathrm{C}\right)$. 


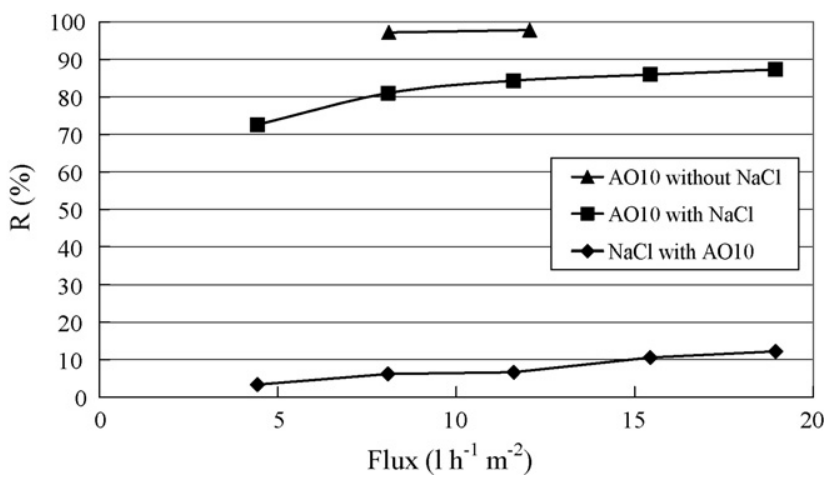

Fig. 13. Observed retention of $\mathrm{AO} 10$ and of $\mathrm{NaCl}$ as a function of flux for $2 \mathrm{AG}$ hollow fibre membrane $\left([\right.$ dye $]=100 \mathrm{ppm},[\mathrm{NaCl}]=170 \mathrm{mM}, u=0.41 \mathrm{~m} \mathrm{~s}^{-1}$, Temp.: $\left.25^{\circ} \mathrm{C}\right)$.

to the higher DG of the 2AG: the retention of AO10 is higher with the 2AG hollow fibre in presence or in absence of salt.

The results presented in Fig. 13 shows the variation of the retention of $\mathrm{AO} 10$ and $\mathrm{NaCl}$ as a function of flux for the $2 \mathrm{AG}$ membrane and a solution at the concentration of $170 \mathrm{mM}$ in $\mathrm{NaCl}$. Unlike results shown in Fig. 10 and 11, $\mathrm{AO} 10$ and $\mathrm{NaCl}$ retentions increase with flux. Here, filtration is carried out in osmotic filtration mode (Peclet number below 1) where the mechanisms of transfer inside the pore are dominating relatively those present in the solution: the convection flux of water increases, while the diffusion of the salts remain constant. Thus, 2AG hollow fibre approaches to the "ideal" membrane presented in the introduction: the AO10 dye is retained whereas salts are not it or little.

\subsubsection{Effect of time on the permeability and the retention}

Fig. 14 relates the flux and dye retention to the time of filtration (15 h of filtration) without recycling of the coloured solution with salt (DR80 with $\mathrm{NaCl}$ ) at the pressure of $2 \times 10^{5} \mathrm{~Pa}$ ( 2 bars) by $1 \mathrm{AG}$ hollow fibre. It is observed that flux decreases slightly during the first $9 \mathrm{~h}$ then remains almost constant. In the same time, the retention of the dye remains stable and higher than $97 \%$. The $\mathrm{NaCl}$ retention measured is almost null $(1-2 \%)$.

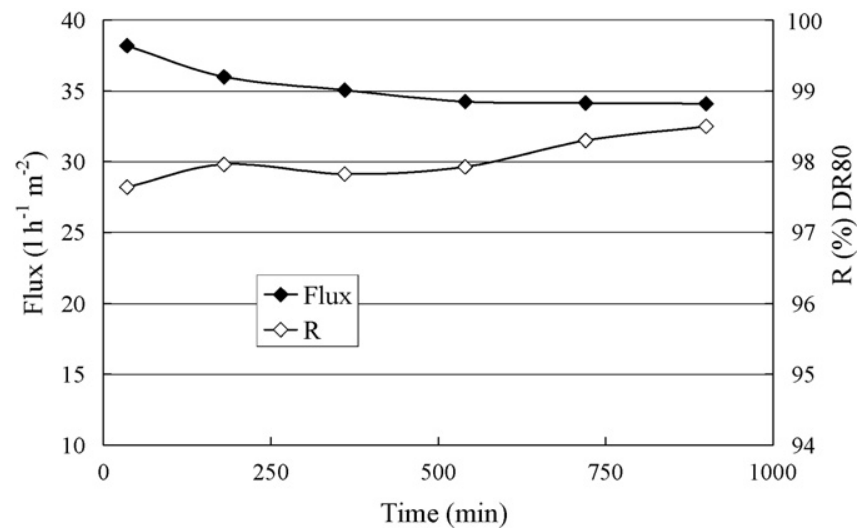

Fig. 14. Flux and observed retention of direct red 80 (DR80) in presence of $\mathrm{NaCl}$ as a function of time for $1 \mathrm{AG}$ hollow fibre membrane ([dye] $=100 \mathrm{ppm}$, $[\mathrm{NaCl}]=510 \mathrm{mM}, u=0.41 \mathrm{~m} \mathrm{~s}^{-1}$, Temp.: $25^{\circ} \mathrm{C}, \mathrm{CF}_{(\text {dye)first point }}=1, \mathrm{CF}_{(\text {dye)last }}$ point $\left.=2.6, \mathrm{CF}_{(\mathrm{NaCl})}=1\right)$.
Thus, the fouling for the 1AG hollow fibre is little important, it makes it possible to retain the dye and to let pass salts. It approaches the characteristics of the "ideal" membrane imagined in the introduction for the filtration of DR80 dye in presence of salt. The same "ideal" membrane has been previously produced in a flat sheet shape [7].

Two hollow fibres were used for the filtration of dye solution. The fouling for the two hollow fibres is low $1 \mathrm{AG}$ and $2 \mathrm{AG}$ and the salt retention is low. The flux is higher for the $1 \mathrm{AG} \mathrm{HF}$ whereas the MWCO is lower and the retention of dyes is higher for the 2AG HF especially in presence of salt. So the 2AG HF can be used to treat anionic dye solution in presence of salt like AO10 even for low molecular weight dye. The 1AG HF could be used for the high molecular weight dye like DR80 to improve the flux compared to the one obtained using the $2 \mathrm{AG} \mathrm{HF}$.

\section{Conclusion}

This work showed that it is possible to obtain, by photografting of vinyl monomers on surface of an ultrafiltration hollow fibre membrane, nanofiltration membranes which are capable to be used for the treatment of saline dye solutions.

The influence of different parameters on the grafting process such as quantity of received energy by the membrane and addition of a photoinitiator on the performances and the characteristics of the membrane was examined. One can underline that rate of grafting are about those used for the spinning of hollow fibres. The setting on line, following a chain of spinning, of a system of grafting is thus possible.

The application of these new modified membranes to the treatment of coloured solutions showed that:

- The fouling problem which exists strongly with polyamide membranes is practically limited and the flux of the dye solutions, even after more than $15 \mathrm{~h}$ of operating, is almost constant. The presence of identical charge on the surface of the grafted membranes and the dye makes it possible to repulse the molecules of dye, by increasing the retention and limiting fouling.

- A MWCO higher than that of the commercial nanofiltration membranes (higher than $1500 \mathrm{Da}$ ) can be selected to concentrate the dye solutions while demineralizing the solution. For example, a negatively charged hollow fibre having a MWCO approximately $5000 \mathrm{Da}$ makes it possible to concentrate the direct red 80 (MW $1373 \mathrm{Da}$ ) with a retention higher than $87 \%$, a high flux $\left(15 \times 10^{-5} 1 \mathrm{~h}^{-1} \mathrm{~m}^{-2} \mathrm{~Pa}^{-1}\left(15 \mathrm{lh}^{-1} \mathrm{~m}^{-2} \mathrm{bar}^{-1}\right)\right)$ and a salt retention lower than $2 \%$. For the dyes of lower molecular weight or less charged, the degree of grafting must be increased in order to decrease the MWCO of the modified membrane. Then an hollow fibre having a MWCO approximately $2000 \mathrm{Da}$ can be used to concentrate the acid orange $10(\mathrm{MW} 452 \mathrm{Da}$ ) with a retention higher than $85 \%$, a high flux $\left(15 \times 10^{-5} \mathrm{lh}^{-1} \mathrm{~m}^{-2} \mathrm{~Pa}^{-1}\left(15 \mathrm{lh}^{-1} \mathrm{~m}^{-2} \mathrm{bar}^{-1}\right)\right)$ and a salt retention lower than $10 \%$.

Finally, different membranes could be produced using the UV photografting to adapt the MWCO and the charge of the 
membranes to the dyes (positively or negatively charged, MW, ...) and to the solution (salt concentration, ...) in order to obtain a high flux (i.e. low fouling membrane), a high retention of dye and a low retention of salt.

\section{Acknowledgements}

This study was financially supported by a doctoral grant from the government of Iran, by Société Française d'Exportation des Ressources Educatives (SFERE) and by Région Midi-Pyrénées. For helpful discussions, the authors wish to thank P. Aptel who has initiated this research.

\begin{tabular}{|c|c|}
\hline \multicolumn{2}{|c|}{ Nomenclature } \\
\hline $\mathrm{CF}$ & concentration factor \\
\hline DG & $\begin{array}{l}\text { degree of grafting (mol monomer } \mathrm{m}^{-2} \text { of mem- } \\
\text { brane) }\end{array}$ \\
\hline$L_{\mathrm{p}}$ & $\begin{array}{l}\text { pure water permeability }\left(\times 10^{-5} 1 \mathrm{~h}^{-1} \mathrm{~m}^{-2} \mathrm{~Pa}^{-1}\right. \\
\left.\left(1 \mathrm{~h}^{-1} \mathrm{~m}^{-2} \mathrm{bar}^{-1}\right)\right)\end{array}$ \\
\hline $\mathrm{NaSS}$ & sodium $p$-styrene sulfonate \\
\hline PI & photoinitiator \\
\hline$R$ & retention $(\%)$ \\
\hline Ret & crosslinker \\
\hline$t$ & time $(\min )$ \\
\hline$T_{\text {irr }}$ & irradiation time $(\mathrm{s})$ \\
\hline$u$ & feed linear velocity $\left(\mathrm{m} \mathrm{s}^{-1}\right)$ \\
\hline$U$ & line rate $\left(\mathrm{m} \mathrm{min}^{-1}\right)$ \\
\hline
\end{tabular}

\section{References}

[1] C. O’Neil, F.R. Hawkes, D.L. Hawkes, N.D. Lourenço, H.M. Pinheiro, W. Delée, Colour in textile effluents-sources, measurement, discharge consents and simulation: a review, J. Chem. Tech. Biol. 74 (1999) 1009-1018.
[2] B. Marrot, N. Roche, Wastewater treatment and reuse in textile industries, a review, Res. Adv. Water Res. 3 (2002) 41-53.

[3] C.A. Buckley, Membrane technology for the treatment of dyehouse effluents, Water. Sci. Technol. 25 (1992) 203-209.

[4] A. Akbari, J.C. Remigy, P. Aptel, Treatment of textile dye effluents using a polyamide based nanofiltration membrane, Chem. Eng. Prog. 41 (2002) 601-609.

[5] B. Van der Bruggen, I. De Vreese, C. Vandecasteele, Water reclamation in the textile industry: nanofiltration of dye baths for wool dyeing, Ind. Eng. Chem. Res. 40 (2001) 3973-3978.

[6] B. Van der Bruggen, B. Daems, D. Wilms, C. Vandecasteele, Mechanisms of retention and flux decline for the nanofiltration of dye baths from the textile industry, Sep. Purif. Technol. 22-23 (2001) 519-528.

[7] A. Akbari, S. Desclaux, J.C. Rouch, P. Aptel, J.C. Remigy, New UVphotografted nanofiltration membranes for the treatment of colored textile dye effluents, J. Membr. Sci. 286 (1-2) (2006) 342-350.

[8] J. Pieracci, J.V. Crivello, G. Belfort, Increasing membrane permeability of UV-modified poly(ether sulfone) ultrafiltration membranes, J. Membr. Sci. 202 (2002) 1-16.

[9] S. Bequet, Procédé de photogreffage en continu de membranes fibres creuses, Ph.D. thesis, Université Paul Sabatier, Toulouse, France, 2003.

[10] T. Goma-Bilongo, A. Akbari, M.J. Clifton, J.C. Remigy, Numerical simulation of a UV photografting process for hollow-fibre membranes, J. Membr. Sci. 278 (1-2) (2006) 308-317.

[11] C. Serra, M.J. Clifton, P. Moulin, J.C. Rouch, P. Aptel, Dead-end ultrafiltration in hollow fibre modules: module design and process simulation, J. Membr. Sci 145 (1998) 159-172.

[12] Colour Index International, Society of Dyers and Colourists, third ed., 1999.

[13] A. Akbari, Elaboration de fibres creuses de nanofiltration par photogreffage: application au traitement de solutions de colorant, Ph.D. thesis, Université Paul Sabatier, Toulouse, France, 2003.

[14] C. Causserand, S. Rouaix, A. Akbari, P. Aimar, Improvement of a method for the characterization of ultrafiltration membranes by measurements of tracers retention, J. Membr. Sci. 238 (2004) 177-190.

[15] M.M. Nasef, H. Saidi, Preparation of crosslinked cation exchange membranes by radiation grafting of styrene/divinylbenzene mixtures onto PFA films, J. Membr. Sci. 216 (2003) 27-38.

[16] B. Kaeselev, P. Kingshott, G. Jonsson, Influence of the surface structure on the filtration performance of UV-modified PES membranes, Desalination 146 (2002) 265-271.

[17] A.I. Schäfer, A.G. Fane, T.D. Waite, Nanofiltration: Principles and Application, Elsevier, Amsterdam, 2005. 